\title{
Efficiency pricing parameters for project appraisal in South Africa (textiles and clothing)
}

\author{
Stefano Mainardi \\ Department of Economics, University of Natal, Private Bag X01, Pietermaritzburg, 3209 Republic of South Africa \\ Received February 1998
}

\begin{abstract}
In developing economies, market prices do not reflect relative scarcities and the fiscal system alone is less than adequate for the achievement of efficiency and equity goals. The use of economic, and eventually social, project appraisal continues to be a necessary policy instrument. Following the OECD-World Bank method of economic costbenefit analysis, the article presents estimates of efficiency pricing parameters relative to two manufacturing sectors in South Africa. These estimates are partly based on medium-term policy options and projections. The choice of a sectoral, rather than a national, focus is explained by the effects of current policy reforms, which affect among others a complex trade regime, and by a varied production structure.
\end{abstract}

\section{Introduction}

The numerous contributions to economic cost-benefit analysis (CBA) are discordant on several issues. Criteria and methods praised by an author, have often been the target of criticisms by others. At a practical level of public decision making, this flourishing of controversial research is reflected by the unclear underpinnings and weak theoretical rigour behind the choice of and changes in threshold levels and methodologies for CBA, as applied by government agencies in developing countries. In recent years, there has been a tendency towards a tightening of projectvetting procedures in many African countries: for instance, investment projects in the Gambia receive public support if they prove to yield at least $15 \%$ of internal rate of return (African Development Bank, unpublished documents).

Some of the reasons for this controversy lie in the fact that, firstly, these techniques often do not lead to unequivocal results: the appropriateness of each technique depends on the objectives and characteristics of an investment project. If applied to independent projects, with no need for rankings, the three most relevant criteria for economic CBA normally provide the same indications about the acceptance or rejection of a project. However, their use is subject to some arbitrariness, in the selection of the discount rate, for the net present value (NPV) and the discounted benefit/cost ratio (DBCR), or of the minimum rate of return, for the internal rate of return (IRR). Provided that costs and benefits are correctly foreseen, a realistic selection of these parameters is fundamental, in view of their impact on the decision as to whether a project is feasible.

Secondly, subjective judgement is exercised in the estimation of adjustment factors accounting for aspects such as the opportunity cost to society, the social importance of domestic savings, and distributional or environmental impact. Thirdly, at a macro level, assumptions of the main body of literature are necessarily simplistic, so as to justify the identification of economic pricing parameters for the whole economy. The analysis is further complicated in the presence of a large subsistence economy sector and market distortions in the formal sector, typical of several less developed countries (LDCs), and even more so if an equity principle is introduced. In order to account for the presence of such market distortions and problems as overvalued exchange rates and high trade barriers, unstable and often institutionally administered prices, low domestic saving propensity, and unequal income distribution, two approaches can be distinguished, namely the UNIDO guidelines (Marglin et al., 1972; UNIDO, 1978) and the OECDWorld Bank guidelines (Little \& Mirrlees, 1968; Squirevan der Tak [henceforth SvdT], 1975). The latter approach offers the advantage of an easier understanding of project costs and benefits by foreign creditors (Ward \& Deren, 1991). A third methodology by Bruno \& Kruger can be considered as a version of the UNIDO approach (Brent, 1990: 179). ${ }^{1}$

Partly accounting for these problems, the analysis in the second section applies the OECD-World Bank approach to estimate economic pricing parameters, namely conversion factors, shadow price of capital, and social rates of discount (SRD), for two South African manufacturing sectors. Concluding remarks follow in the third section.

\section{Macroeconomic estimates}

\section{Methodological remarks and sources}

Unlike two previous studies based on the same approach, that is Mashayekhi (1980) for Turkey and Adhikari (1988) for Nepal, the estimation of macroeconomic parameters deemed to be valid for the whole economy is considered to be an unrealistic target for South Africa, due to the peculiar features of the economy and its institutional environment. Attention is rather paid to the textiles and clothing industries, which represent two of the most protected sectors in South Africa and are likely to suffer from severe price distortions. ${ }^{2}$ Detailed information on the proposed partial phasing out of trade protection for the products concerned until the beginning of the next decade is presented in BTT (1995).

The domestic market in South Africa is highly segmented, and presents relatively more striking differences among producers and consumers than other developing 
economies.' Furthermore, the trade policy followed by this country has led to one of the most complex systems of trade protection in the world. The weighted average nominal protection in 1993-1994 was estimated to be 21-22\%, but trade items are subject to a wide variety of tariff rates. The normal maximum rate of $100 \%$ lies above the maximum rate applied by most LDCs (IMF, 1994: 48-49). For some items, tariff rates exceed $100 \%$ (up to more than $1300 \%$ !). ${ }^{4}$ In terms of economic sectors, whereas mining products are offered almost no tariff protection, manufacturing consumer goods are highly protected compared to the tariff treatment applied in other economies, with other sectors occupying an intermediate position (Fallon-da Silva, 1994: 344). The items identified by the tariff system are more than 13000, of which over 2600 are listed for textiles and clothing. To offset balance of payments problems related to the effects of sanctions, since 1988 import surcharges amounting to $5 \%$, up to $40 \%$ of the import value have been applied to various items and have been maintained despite the changing conditions (Hatty, 1993: 131).

As the most relevant and comprehensive policy instrument established to assist exporters (Fallon-da Silva, 1994: 85, 349-359), the General Export Incentive Scheme (GEIS) became operative in April 1990, replacing a more complicated subsidy programme. Relatively more labourintensive manufacturing sectors, identified as category 4 , were granted by these export assistance schemes an average allowance of nearly $12 \%$ of export values up to the mid-1990s, followed by recent slight reductions and, eventually, a gradual complete removal. This allowance has been taxable since 1985, although the lack of transparency and the variety of complementary measures actually imply additional subsidies, partly tax-free. At the sectoral level, since April 1993, as part of the restructuring plan for textiles and clothing, a Duty Credit Certificate Scheme (DCCS) has offered special rredit to exporters, for exports outside the SACU area, on duties payable on related imports of certain inputs (DTI, 1995). Following official policy recommendations, the DCCS is expected to be subject to a progressive phasing down and eliminated by the beginning of the next century (Panel, 1994: 144).

A second distinction from the aforementioned studies concerns the suitability of recent figures for variables used in this analysis as representative for their performance in the near future. Mashayekhi (1980) relies mostly on average estimates for the overall economy and individual commodity categories (namely consumer, intermediate and capital goods) for the period 1974-1978, which he assumes to be suited to economic and social project appraisal in Turkey 'in the next five years' (1980: 1). Adhikari (1988) provides estimates of conversion factors' and national economic parameters for the Nepalese economy and major traded and non-traded goods, which are mainly based on the period 1970-1983. While these estimates are thought to be 'readily available for practical purposes', the latter author cautions the reader by suggesting the need for updating these estimates, given their sensitivity to changing government policies and macroeconomic conditions (Adhikari, 1988: 240).
In a rapidly changing institutional and economic environment as occurring in South Africa, one cannot assume the high and widespread trade restrictions and factor price dis. tortions will hold over the lifetime of projects which are to be implemented in the near future (Fallon-da Silva, 1994)! Realistic estimates can be obtained only if current government objectives and envisaged policy measures are accounted for. For this reason, while variables such as the marginal productivity of capital and the marginal saving propensity were estimated on the base of past performance, the estimation of conversion factors and sectoral parameters was based on indicative-normative or projected figures regarding variables such as tariff treatment and foreign trade. Whereas most literature contributions tend to exclusively rely on historical data, this view is shared by a World Bank study on shadow pricing for Pakistan (Nas, 1996: 204).

The OECD-World Bank approach was preferred also because of the tradable nature of the sector cases focussed on. In South Africa this seems to hold true especially for textiles. For manufacturing as a whole the degree of market openness, as measured by the ratio of foreign trade to domestic production, has tended to amount to nearly $30 \%$ in recent years. While the clothing industry has experienced an openness of $10-15 \%$ over the last two decades, the textile industry has had an average value of $35 \%$ over the period 1972-1993. Although this has mainly been due to a marked output contraction in real terms, an upward trend in openness has moreover affected textiles since the late 1980 s, so as to raise it above $50 \%$ by 1993 . Sectoral information was obtained from IDC (1995) and BTT (1995), while for population figures and the savings function World Bank (1995) was relied on. World Bank and IDC annual data were originally expressed in constant 1987 and 1993 prices, respectively. All data refer to the geographical area of the Republic, thus including the four former independent states (Transkei, Bophuthatswana, Venda and Ciskei).

\section{Empirical results}

The South African textiles and clothing industries are facing economic difficulties due to declining profitability and increasing cost vs.productivity imbalance (BTT, 1995). The latter problem is associated with inputs partly available only at above world prices, outdated technology, and insufficient job retraining. A revised tariff structure over the next few years is regarded by BTT as a tool aimed at (i) aligning these sectors with the envisaged phasing out of the Multi-Fibre Arrangement (MFA), which will end their special status and will integrate the MFA into the WTO directives; (ii) fostering their international competitiveness and export orientation; and (iii) establishing a more transparent and stable tariff structure. While these objectives are seen as functional to a long-term strategy of self-sustaining growth, they should not be at the cost of excessive shortterm employment losses (to be kept 'minimal') or hinder new employment creation (BTT, 1995: 16-17).

The phasing down of ad valorem import duty rates during the period $1995-2002$ is foreseen to progressively reduce these rates by nearly half their initial levels. With respect to textiles, yarns would be subject to tariff rebates 
from $30 \%$ in 1995 to $15 \%$ in 2002 , and fabrics to analogous rebates from $42 \%$ to $22 \%$; for clothing, most ad valorem rates would fall from $84 \%$ to $40 \% .^{7}$ For this analysis, the envisaged import tariff levels for the two major components of the textile industry, namely yarns and fabrics, were averaged (Table 1). No information was available with respect to other trade controls, such as import quotas and licences. The revised trade regime will be complemented with government assistance, through subsidised interest rates, in areas including technology upgrades, training of employees, infrastructure development, and integration of the informal sector (Panel, 1994). In order to stimulate exporters to improve their competitiveness, the newly revised DCCS (see first part of section 2) requires exporters of textiles and clothing to devote at least $4 \%$ of the wage bill to internal training, and to be continuously assessed through a Productivity Performance Monitoring Scheme administered by the NPI (DTI, 1995).

Conversion factors were estimated by trying to account for export subsidies, besides import duties (see CF in the Appendix). Alternatively, Schydlowsky's force of tariff method $\left(C F_{F T}\right)$ restricts the assessment of world vis à vis domestic prices of tradables to imported goods, under the simplistic assumption that only imports are affected by additional project-related foreign exchange (Adhikari, 1988: 83). For the CFs, due to lack of precise information, subsidy rates tracing the tendency outlined in the first part of the second section were considered a possibly optimistic scenario, while the absence of comparable data on unit values of domestic prices and imports prevented the use of a

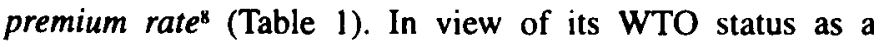
country in transition, South Africa may be granted longer phasing out periods for export incentives (Panel, 1994: 141). Furthermore, subsidy averages conceal substantial differences across product categories, depending on the degree of processing, from nearly $5 \%$ for some textile products to a maximum of $19.5 \%$ of export values for clothing (Panel, 1994: 87).

Flows of imports in c.i.f. prices and exports in f.o.b. prices over the period 1994-2002, were forecast based on mixed extrapolation models, with regressors given by a first order (and eventually second order) autoregressive component and a linear trend (Pindyck \& Rubinfeld, 1986: chapter 15). 9 The whole estimation period (1972-1993; IDC, 1995) was used as a baseline for forecasting textile trade flows, and preference was given to models predicting a consistent gradual opening of the economy to increasing

\begin{tabular}{|c|c|c|c|c|}
\hline \multicolumn{5}{|l|}{ Textiles } \\
\hline Parameter/year & 1993 & 1996 & 1999 & 2002 \\
\hline ad valorem rates of import duties (\%) & 36 & 33.5 & 26 & 18.5 \\
\hline $\mathrm{CF}_{\mathrm{FT}}$ & 0.73 & 0.75 & 0.79 & 0.84 \\
\hline $\begin{array}{l}\text { CF } \\
\text { [\% export subsidies] }\end{array}$ & $\begin{array}{l}0.79 \\
{[12]}\end{array}$ & $\begin{array}{l}0.81 \\
{[10]}\end{array}$ & $\begin{array}{l}0.86 \\
{[5]}\end{array}$ & $\begin{array}{l}0.91 \\
{[0]}\end{array}$ \\
\hline \multicolumn{5}{|l|}{ Other parameters (1993 only) } \\
\hline q $\left(\mathrm{SCF} / \mathrm{CF}_{\mathrm{k}}=0.90\right)$ & $\begin{array}{l}\mathrm{q} \\
\left(\mathrm{SCF} / \mathrm{CF}_{\mathrm{k}}=0.95\right)\end{array}$ & CRI & $\begin{array}{l}v \\
\left(\mathrm{SCF} / \mathrm{CF}_{\mathrm{k}}=0.90\right)\end{array}$ & $\begin{array}{l}\text { ARI } \\
\left(\mathrm{SCF} / \mathrm{CF}_{\mathrm{k}}=0.90\right)\end{array}$ \\
\hline \multirow[t]{2}{*}{10.3} & 10.8 & $2.5(n=1 ; \rho=2)$ & $5.2(n=1 ; \rho=2)$ & $4.1(n=1 ; \rho=2)$ \\
\hline & & $5.6(n=1.2 ; \rho=5)$ & $2.3(n=1.2 ; \rho=5)$ & $6.6(n=1.2 ; \rho=5)$ \\
\hline \multicolumn{5}{|l|}{ Clothing } \\
\hline Parameter/year & 1993 & 1996 & 1999 & 2002 \\
\hline ad valorem rates of import duties (\%) & 84 & 78 & 60 & 40 \\
\hline $\mathrm{CF}_{\mathrm{FT}}$ & 0.54 & 0.56 & 0.62 & 0.71 \\
\hline $\begin{array}{l}\text { CF } \\
\text { [\% export subsidies] (Hyp. A) }\end{array}$ & $\begin{array}{l}0.75 \\
{[12]}\end{array}$ & $\begin{array}{c}0.73 \\
{[10]}\end{array}$ & $\begin{array}{l}0.77 \\
{[5]}\end{array}$ & $\begin{array}{l}0.84 \\
{[0]}\end{array}$ \\
\hline $\begin{array}{l}\text { CF } \\
\text { [\% export subsidies] (Hyp. B) }\end{array}$ & $\begin{array}{l}0.75 \\
{[12]}\end{array}$ & $\begin{array}{l}0.78 \\
{[10]}\end{array}$ & $\begin{array}{l}0.84 \\
{[5]}\end{array}$ & $\begin{array}{l}0.92 \\
{[0]}\end{array}$ \\
\hline \multicolumn{5}{|l|}{ Other parameters (1993 only) } \\
\hline $\begin{array}{l}q \\
\left(S C F / C F_{k}=0.90\right)\end{array}$ & $\begin{array}{l}q \\
\left(S C F / C F_{k}=0.95\right)\end{array}$ & CRI & $\left(\mathrm{SCF} / \mathrm{CF}_{\mathrm{k}}=0.90\right)$ & $\begin{array}{l}\text { ARI } \\
\left(\mathrm{SCF} / \mathrm{CF}_{\mathrm{k}}=0.90\right)\end{array}$ \\
\hline \multirow[t]{2}{*}{36.4} & 38.5 & $3.0(n=1 ; \rho=2)$ & $16.1(n=1 ; \rho=2)$ & $10.0(n=1 ; \rho=2)$ \\
\hline & & $6.2(n=1.2 ; p=5)$ & $7.8(n=1.2 ; \rho=5)$ & $12.5(n=1.2 ; \rho=5)$ \\
\hline \multicolumn{5}{|l|}{ Macroeconomic parameters (1993 only) } \\
\hline SER $(S C F=0.85)$ & \multicolumn{4}{|l|}{ SER $($ SCF $=0.90)$} \\
\hline 3.85 (R per USD) & \multicolumn{4}{|l|}{3.63 (R per USD) } \\
\hline \multicolumn{5}{|c|}{ Hyp. A: dynamic growth scenario for imports } \\
\hline \multicolumn{4}{|l|}{ Hyp. B: slow growth scenario for imports } & \\
\hline
\end{tabular}


imports. The use of the baseline period is likely to provide conservative forecasts for clothing imports (and leads to residual autocorrelation), since these flows appear to pick up from a slack performance only from the late 1980 s and early 1990s: the radical tariff changes envisaged by the BTT for clothing let hypothesise a more dynamic future performance of imports for this sector, which can be modelled by a mixed autoregressive quadratic trend model over the period 1980-1993. Following the latter estimates, the South African trade surplus in this sector would tend to shrink progressively and would almost disappear during the first half of the next decade. For clothing exports, the Upattern traced during the late part of the period suggested to adopt the same model and estimation sub-period as for the dynamic import scenario.

Based on these forecasts and the envisaged duty rates, conversion factors for a few years, including the last year of the baseline period, are presented in Table 1. The force of tariff method tends to accentuate the effects of trade distortions on domestic prices, especially for clothing. For this sector, the dynamic growth forecasts for imports were preferred, although both sets of forecasts were used for the standard sectoral conversion factor (Hypotheses A and B in Table 1, respectively). Except for the CF for clothing under the assumption of a high rate of growth of both trade flows, all conversion factors show consistently increasing values over the forecast period. The 1993 values obtained with the weighted average tariff and subsidy rate method are close to those of Mashayekhi (1980: 23) for consumption goods in Turkey in the mid-1970s, and similar or slightly lower than consumption conversion factors obtained by other studies for other middle-income economies, reported by Curry \& Weiss (1993: 264) (0.86 for Botswana in 1987; 0.74 for Mexico in 1986).

The marginal productivity of capital was estimated through a Cobb-Douglas production function. Fixed capital stock by manufacturing activity is measured by the IDC (1995) after providing for depreciation, while employment figures include casual and seasonal workers. For textiles, the function was applied to the period 1972-1989: since 1990 the production of textiles has been drastically reduced in spite of only minor downward adjustments in the capital stock. This implies a bias in the estimates if the last few years of the series are included, with even a reversal of the sign of the estimated parameter. ${ }^{10}$ A substantially different pattern is identifiable for the clothing industry, whereby a seemingly negative relationship between output and capital is explained by a relatively better performance of the former variable as opposed to a declining trend in the capital stock. The unrealistic estimate of a negative productivity of capital is avoided by assuming that the joint capital stock of the two manufacturing sectors is a more relevant proxy of the capital factor for clothing, being this sector largely constituted by downstream production activities with backward linkages with textiles.

The two elasticity estimates are 0.38 and 0.92 , respectively for textiles and clothing ( $\alpha$ : Appendix). A t-test, applied on a suitably transformed equation, cannot reject the null hypothesis of constant returns to scale for textiles, while it does support evidence of increasing returns for clothing at the $90 \%$ confidence level (the estimated parameters for the labour factor are 0.74 and 0.87 , respectively). A trend variable accounting for technical change was not added to the regressions because of multicollinearity. The incremental output/capital ratios over the baseline period were found to be on average 0.30 for textiles and 0.44 for clothing, if consistency with the above estimations is maintained (excluding the last four years for textiles, and once gross fixed investment of the two sectors is aggregated for clothing). The resulting respective marginal products of capital at domestic prices are 0.114 and 0.405 (MPK: Appendix).

These estimates should then be weighted by the ratio of the SCF to the conversion factor for capital goods (SvdT, 1975: 110-111; Appendix). As considered earlier, these two general conversion factors can not easily be estimated for South Africa, in view of a wide uncertainty and variability over time, which prevent an estimation of economywide parameters. In the beginning of the 1990s, the weighted average rate of protection for the whole economy was $28 \%$, and for capital goods $19 \%$ (Fallon-da Silva 1994: 344). One can therefore assume the ratio to have been and likely to remain lower than one, as also found by previous studies for other countries. Two alternative ratios for these conversion factors," applied to the marginal productivity estimates, yield the results on the opportunity cost of capital at border prices $(q)$ in Table 1 . The estimates for the textile sector appear to be in line with similar estimations at the national level for other middle-income economies, generally lying in the range 9-12\% (Mashayekhi, 1980: 31; Curry \& Weiss, 1993: 264-266).

The consumption rate of interest (CRI) reflects the economic and social preferability of present vis à vis future consumption. In the OECD-World Bank approach, this parameter is supposed to depend on (i) distributional aspects; and (ii) the social time preference rate (Brent, 1990: 71-72, 92; Appendix). On the one hand, in terms of point (i), if a positive influence of economic growth on future generations' welfare is expected, intertemporal equality considerations will entail a lower weight on future consumption. These aspects are therefore reflected by the growth of per capita consumption $(g)$ and the social elasticity of marginal utility of consumption $(n)$. The rate of pure time preference $(\rho)$, on the other hand, normally implies a further negative premium on future generations' consumption, due to myopic or irrational views by society and government. Both $n$ and $\rho$ are policy-related parameters, generally based on the project analyst's interpretation of government objectives. ${ }^{12}$

The parameter $n$ reflects society's (or government's) attitude towards inequality in income distribution: the larger its value, the greater the discounting on richer household income, and hence the greater the social benefit derived from projects associated with improved relative economic and social conditions for the poorest. According to SvdT (1975), values of $n$ close to 0 or 2 can be considered extreme cases, whereas for most governments $n$ is likely to be near unity, thus entailing a mix of partly contradictory government objectives. For $\rho$, the same authors recommend the use of low values (for example between 0 and $5 \%$ ), since 
the government is aware of its obligations towards future generations.

The present government in South Africa is highly concerned with both distributional and growth objectives. Two alternative hypotheses were therefore made on the values of the parameters $n$ and $\rho$ for the current and forthcoming policy environment: (i) a slightly more growth-oriented policy scenario, with these parameters assumed to be equal to 1 and 2 , respectively (redistribution through growth); and (ii) a scenario characterised by a relatively greater medium-term policy involvement in income redistribution (growth through redistribution), with $n$ and $\rho$ being 1.2 and 5 , respectively.

With reference to the third component of the CRI, $g$, both sectors have been subject to a slack growth in consumption over the period analysed, especially if their performance in the second half of the period is focussed on. In per capita terms, a relatively more marked contraction is registered by textiles, with a declining trend in the 1980s and early 1990s. Average annual compound growth rates for per capita private consumption in the sub-periods 1972-1981, 1981-1990, and 1990-1993 are found to be: $2.2,-5.4$, and -5.9 , for textiles; and $4.0,-4.1$ and 0.2 , for clothing. Rather than estimating it econometrically, the parameter $g$ was set equal to $0.5 \%$ for textiles and $1 \%$ for clothing, in view of the tendency of clothing consumption per capita to grow at nearly twice the pace of textiles during expansions. The results for the CRI in the two hypotheses are reported in Table 1 . The values of the ranges are slightly higher than those of an analogous sensitivity analysis for the Turkish economy (Mashayekhi, 1980: 37).

For an estimate of the value of public income, the OECD-World Bank approach assumes an optimal allocation of government expenditures among different uses: at the margin, the social value of these expenditures in different areas is supposed to be equal. This assumption can be relaxed once the analysis is carried out at the sectoral level. ${ }^{13}$ If one assumes that $q$ reflects the marginal product on public capital expenditure received by someone at the average level of consumption (eventually for each sector), and if the returns on the possible reinvestment of public funds are ignored, the equivalent value of consumption would be $q / C F_{c}$, which needs to be discounted further by the CRI (SvdT, 1975: 106; Brent, 1990: 47). ${ }^{14}$ Results seem to indicate that the marginal social value of foreign exchange in the public sector can be regarded to be worth nearly 3.5-4 times the marginal social value of consumption in textiles, and approximately 12 times the analogous value for clothing, if one averages the values for the two hypotheses (Table 1). Obviously, the gap appears relatively higher in the case of the redistribution through growth scenario.

The accounting (or public income) rate of interest (ARI) represents the most relevant parameter in economic CBA following the OECD-World Bank methodology. It measures the social IRR of marginal public [and private: note 2] investment, at efficiency prices (SvdT, 1975: 114). Similarly to the CRI, it can be decomposed into two components, so as to adjust the marginal productivity of capital (see note 10) by distributional factors implied by the sav- ings versus consumption alternative. If $s$ is the share of forgone income which would have been saved in the absence of the project(s), then the rate of forgone savings and forgone consumption are respectively given by $s q$ and $(I-s) q$. The first component is directly expressed in terms of the numeraire (investment, or public income, unlike the UNIDO approach based on consumption). The second component is discounted by SvdT (1975) through a doubleadjustment procedure (Brent, 1990: 70-73), by dividing it by $v$ and by the conversion factor for consumer goods. Since the reciprocal of $v$ represents the value of consumption in terms of government income (shadow price of consumption), the first adjustment converts consumption into units of public income (numeraire). The second adjustment, in turn, converts consumption into efficiency units, by giving a different weight in terms of investment use to, for example, the consumption of trucks than other consumer goods. ${ }^{15}$

To estimate the parameter $s$, gross domestic savings were regressed on gross domestic income (which includes gross domestic savings, private consumption and general government consumption - World Bank, 1995), over the baseline period 1972-1993 and the sub-period 1980-1993. Although both variables do follow a similar pattern in terms of fluctuations over time, domestic savings have tended to stagnate in real terms compared to an overall positive trend in real income, thus suggesting a very low marginal saving propensity for the periods analysed. One should however take into account the different procedures and uncertain results emerging from the literature concerned (SvdT, 1975: 112-113; Brent, 1990: 75), with $s$ being generally considered underestimated, and often accompanied by residual autocorrelation. This led to preference of a Koyck-type transformation, which includes a declining lagged influence of past values of income on savings, besides the contemporaneous effect, and proved to yield statistically significant estimates. While the short-term impact is found to be very low, the long-run propensity to save results to be 0.21 for both periods. For the two scenarios, the ARI for textiles are close to the central value of a sensitivity analysis of the ARI for Turkey (Mashayekhi, 1980: 42), while relatively higher parameters are obtained for the clothing industry.

\section{Conclusions}

South Africa has been experiencing several of the structural problems affecting most middle-income economies, such as high unemployment levels, and insufficient domestic and foreign savings compared to development requirements. As common in these economies, these structural imbalances have been aggravated by the effects of high and widespread trade protection, export subsidies, misaligned exchange rates, and distortions to domestic factor prices. The existence of these structural disequilibria and price distortions points to the need for assessing investment projects on the base of economic efficiency prices, rather than domestic market prices. In the presence of high import tariffs and heavily subsidised exports, failure to rely on efficiency prices would provide a biased picture of real costs and benefits of new investment projects for society, 
with an overstatement of the costs of potential imported inputs as well as of the economic benefits accruing from an increased scope for foreign exchange earnings. If unaccompanied by adequate supply measures, both sets of measures would encourage the maintenance (or discourage the restructuring) of internationally uncompetitive domestic production activities, and an inefficient allocation of domestic resources.

This analysis has aimed at identifying efficiency pricing parameters for economic CBA relative to two South African manufacturing sectors which are particularly affected by the above imbalances and distortions. As in most developing economies, the effects of shadow pricing in South Africa, following the OECD-World Bank methodology, would imply a scaling down of prices of non-traded goods, although distinctions are needed at the sectoral level in view of the extremely complex foreign trade regime. Studies on economic project appraisal in other countries have often found the efficiency discount rates estimated at the national or sectoral level to be lower than the equivalent rates used for financial analysis (Mashayekhi, 1980: 42; Phillips, 1986: 18). This has typically been the case of highly protected industries: these results may lead to excessively optimistic conclusions about the economic efficiency and social returns of investment projects undertaken in these industries.

With regard to the estimations of this study, some countervailing arguments should be considered. Policy-related assumptions, concerned with income redistribution objectives and expectations of sustained economic recovery, have led to assign reasonably high values to individual components of the CRI. This has indirectly influenced results for the ARI as well. For the latter parameter, moreover, the macro approach adopted to estimate $q$ may have even led to an overestimation, since the functional form neglects the contribution of other factors of production, such as technical progress and human capital (Mashayekhi, 1980: 29; Adhikari, 1988: 112). This can particularly concern the case of clothing, which is likely to benefit, according to regression results, from increasing returns to scale and substantial spillovers from inter-sectoral production links with textiles. Other approaches to an estimation of $q$, however, are subject to other problems and uncertainties, as discussed by Mashayekhi (1980).

Expectedly, on the whole the results point out how social discount rates would need an increase of 0.5 to nearly 6 percentage points for the relatively more protected sector, clothing, compared to textiles, according to different hypotheses. An analogous increase of about 2.5 or 3 percentage points would be suggested for a shift in development priorities from policies relatively more concerned with growth objectives to alternative policies with a clearer preference for a faster fulfillment of urgent social requirements. This shift would entail a slowdown in the implementation of measures such as general infrastructure development and human capital formation, and greater emphasis on labourintensive investment, especially in housing, roads and community centres in the poorer regions.

\section{Notes}

1. Criteria of and methodological approaches to economic CBA, and their applicability to LDCs, are assessed in a longer paper by the author for the EBM Conference, Port Elizabeth, November 1996 (from which this article originated).

2. In narrowly practical terms, it would be more appropriate to choose a category of projects subject to direct state intervention, typically related to infrastructure and public utilities. Besides problems of data availability and reliability, this choice can still be justified in view of the price distortions affecting these sectors, and the suitability of economic CBA to private investment projects and production programmes on which the government exercises some guidance (Squire, 1989: 1094; Meier, 1995: 558). In South Africa, a newly proposed Textile and Clothing Authority (TCA) is expected to monitor the performance and evaluate the results of projects and programmes ... with a view to advising the Minister' (Panel, 1994: 171). More broadly, one can advocate the usefulness of these criteria for the evaluation of private sector projects from an economic and social welfare perspective (Drèze \& Stern, 1987: 910). In recent years, there seems to be a shift as to how shadow prices are mainly used, from an individual project level increasingly towards development policy analysis in areas such as trade liberalisation and industrial restructuring (Chowdhury \& Kirkpatrick, 1994: 121-122).

3. While constrained by data unavailability, a separate computation of conversion factors for the urban and the rural population would be desirable for economies with highly skewed income distribution (Mashayekhi, 1980: 22). Capital market segmentation and related resource misallocation similarly hamper a correct estimation of the marginal productivity of capital for a developing economy as a whole (Mashayekhi, 1980: 34).

4. Hattey (1993: 130) reports that South Africa has 'more tariff rates than any other country', while also holding the widest range in these tariffs.

5. The standard conversion factor is a weighted average ratio of world to domestic prices for the main sectors of the economy (Curry \& Weiss, 1993: 105). The CF in the Appendix is its equivalent for a specific sector. The UNIDO version of the SER could be readily transformed into the OECD-World Bank SCF (Appendix) only if the method of weighting the domestic to world price ratio were the same, which is not the case for the two guidelines (Adhikari, 1988: 83).

6. Fallon \& Da Silva (1994: 343 ) argue that, 'because of the frequent changes in the tariff schedule, any analysis of the South African trade regime is a snapshot valid for only a short time'.

7. The tariff reductions have so far been implemented according to the BTT schedule, except for a three-month delay. In December 1996, import duties were $28 \%, 39 \%$, and $78 \%$, for yarns, fabrics and clothing, respectively (Cloete, 1997).

8. Adhikari (1988: 81-89) uses the same formula of this analysis, besides alternative estimates which account for an import control premium, while Mashayekhi (1980: 17) simulates different values for this premium.

9. The models were of the form: $y=\alpha+\beta y_{.1}+\gamma t+\varepsilon$, where $y$ is the original (or log-transformed) variable (for example, textile imports) and $t$ is a trend term. Econometric results of regression equations, including the standard tests of violation of OLS assumptions, are not shown because of space reasons. 
10. Other studies find strongly negative productivity of capital for certain countries and industries. These results are obviously likely to be due to inaccuracies in the statistical treatment of the data, or unreliability of these data (Phillips, 1986: 17). The marginal productivity of capital is defined as the net return earned by a marginal unit of investment at border prices with all inputs and outputs measured at efficiency prices, that is the efficiency measure of the interest rate (Brent, 1990: 72). It corresponds to the marginal rate of transformation between present and future foreign exchange (Mashayekhi, 1980: 29).

11. The two alternative levels assumed for the ratio $\mathrm{SCF} / \mathrm{CF}_{\mathrm{k}}$ would be consistent with a conversion factor for capital goods lying within the range $0.89-1$, given the SCF values used for an estimate of the SER (Table 1). This is consistent with the relatively lower tariff protection offered to capital goods, compared to the national averages for manufacturing and the economy as a whole. The SCF values similarly appear to provide a reasonable guideline for an estimation of the shadow exchange rate in 1993, when the official rate was 3.27 rand per dollar. This is not applicable to the devaluation events in 1996.

12. For an individual at the average consumption level $c$, SvdT adopt a constant elasticity marginal utility function, expressed by $U_{c}=c^{-n}$. Using continuous time discounting, the present value is given by: $W_{c}=c_{1}^{-n} e^{-p 1}$ (symbols in the Appendix). Taking the negative derivative of this function with respect to time, and recalling the definition of the CRI (Brent, 1990: 69, 90-91), one obtains:

$C R I=-\left(d W_{c} / d t\right) / W_{c}=\rho c_{t}^{-n} e^{-\rho t}+n c_{i}^{-n-1} e^{-p t} d c_{l} / d t=\left\{c_{1}^{-n} e^{-p t}\right.$

$\left.\left[\rho+n c_{1}^{-1} d c_{1} / d t\right]\right\} / c_{1}^{-n} e^{-\rho t}=\rho+n g$.

This formula has been criticised with reference to (i) the necessity for a parameter $\rho$; (ii) the representativeness of $g$ for specific target groups; and (iii), even if the condition (ii) were to be satisfied, a possible misspecification of the marginal utility function (Price \& Nair, 1985). Regarding (iii), marginal utility can be expected to approach infinity at survival (b), rather than zero, consumption, thus suggesting a replacement of $c$ by $(c-b)$ for LDCs (Price \& Nair, 1985: 527). Objections are also raised against the reasons for the negative exponential in the marginal utility function (Lumby \& Saville, 1996: 332334). Failure to adjust may entail an understatement of the SRD, especially for poor income groups. By contrast, an overstated SRD might result from point (ii), in the case of a longduration project concerning a beneficiary group with consumption growing slowly. Even if at an aggregate level, this study examines $g$ relative to two manufacturing sectors, separately.

13. In social CBA, another distinction concerns the social value of a unit of consumption to a particular consumption group relative to the average (group) social value of consumption. Distribution parameters $d$ accounting for intragenerational inequality, are represented by the ratios of the marginal utilities for the two groups, and depend on (i) the respective consumption levels; and (ii) the inequality aversion parameter $n$ (Brent, 1990: 44-47). The additional consumption of an individual consuming only one-tenth of the average would then be attributed a social value respectively ten times (for $n=1$ ) or nearly sixteen times (for $n=1.2$, i.e. $d=10^{1.2}$ ) that of an average consumer (for example, for a textile production project located in a poor urban area). This analysis was limited to economic pricing parameters, with $d$ fixed to 1 and 'average' parameter results for CRI, $v$, and ARI.
14. SvdT (1975: 105-106) argue that, even if the assumption of constancy in the parameters composing $v$ is still likely to imply an upward bias, this formula would probably lead to a lower bound value for an estimate of public income, compared to what is obtained following an alternative procedure.

15. The ARI can be interpreted as a weighted average of the CRI and the investment rate of interest narrowly defined - the opportunity cost of capital (IRI). As such, the ARI is regarded as a preferable SRD, since it does not depend on a priori assumptions on potential alternative uses of the resources of a project (Lumby \& Saville. 1996). Given the formulae of the value of public income and the ARI used here (applied to consumer goods for the two sectors separately, with no attempt to estimate $\mathrm{CF}_{\mathrm{c}}$ for the economy or individual items), the second component of the ARI can be simplified as follows (Appendix): [(1-s) - CRI].

\section{Acknowledgement}

The author wishes to thank J. Swanepoel for the computerised IDC Sectoral Data Series, and the University of Natal/ URF for the financial support.

\section{References}

Adhikari, R. 1988. Manufacturing industries in developing countries: an economic efficiency analysis of Nepal. Aldershot: Avebury.

Board on Tariffs and Trade (BTT): Amendment of the Tariff Structure and Rates of Duty Applicable to Textiles and Clothing Classifiable under Chapters 50 to 63, Report No. 3558, Pretoria.

Brent, R.J. 1990. Project appraisal for developing countries. Hemel Hempstead: Harvester-Wheatsheaf, .

Chowdhury, A. \& Kirkpatrick, C. 1994. Development policy and planning. London: Routledge.

Cloete, G. 1997. Textiles showing signs of life, F\&T Weekly ( $F i$ nansies en Tegniek), 9 May: 23.

Curry, S. \& Weiss, J. 1993. Project analysis in developing countries. London: MacMillan.

Department of Trade and Industry (DTI). 1995. Revised guidelines, rules and conditions for participation in the Duty Credit Certificate Scheme for Exporters of Textiles and Clothing (DCCS). September, Pretoria.

Drèze, J. \& Stern, N. 1987. The theory of cost-benefit analysis. In Auerbach, A.J. \& Feldstein, M. Eds. Handbook of public economics. Amsterdam: North Holland, vol. II: 909-989.

Fallon, P. \& Pereira da Silva, L.A. 1994. South Africa. Economic performance and policies. Discussion Paper No. 7, Washington DC: World Bank.

Hatty, P.R. 1993. The South African trade policy debate: a business perspective. In P.H. Baker, P.H., Boraine, A. \& Krafchik, W. Eds. South Africa and the World Economy in the 1990 s. Cape Town: D. Philip Publisher, pp. 126-136.

Industrial Development Corporation (IDC): Sectoral Data Series. Manufacturing 1995. Johannesburg.

International Monetary Fund (IMF). 1994. International trade policies. The Uruguay Round and beyond, vol.II. (Background papers.) Washington DC.

Little, I.M.D. \& Mirrlees, J.A. 1969. Manual of industrial project analysis in developing countries. Paris: OECD.

Lumby, A.B. \& Saville, A.D. 1996. The discounting debate: accounting for the future in the past and the present, The South African Journal of Economics, 64(4): 320-340. 
Marglin, S., Sen, A. \& Dasgupta, P. 1972. Guidelines for project evaluation. Vienna: UNIDO.

Mashayekhi. A. 1980. Shadow prices for project appraisal in Turkey, Staff Working Paper No. 392. Washington DC: World Bank.

Meier, G.M. 1995. Leading issues in economic development. Oxford: Oxford University Press.

Nas, T.F. 1996. Cost-benefit analysis. Theory and application. London: SAGE.

Panel and Task Group for the Textile and Clothing Industries. 1994. Long-term strategic plan for the textile and clothing industries in South Africa. March, Pretoria.

Phillips, D.A. 1986. Pitfalls in estimating social discount rates: a case study. Project Appraisal, 1(1): 15-20.

Pindyck. R.S. \& Rubinfeld, D.L. 1986. Econometric models and economic forecasts. Singapore: McGraw-Hill.

Price, C.\& Nair, C.T.S. 1985. Social discounting and the distribution of project benefits, The Journal of Development Studies, 21(4): 525-532.

Squire, L. 1989. Project evaluation in theory and practice. In Chenery, H. \& Srinivasan. T.N. Eds. Handbook of development economics. Amsterdam: North Holland, vol. II: 1093-1137.

Squire, L. \& Van der Tak, H. (SvdT). 1975. Economic analysis of projects. Baltimore: Johns Hopkins.

UNIDO. 1978. Manual for the preparation of industrial feasibility studies. New York: United Nations.

Ward, W. \& Deren, B. 1991. The economics of project analysis, EDI. Washington DC: World Bank.

World Bank. 1995. World tables 1995. Washington DC

\section{Appendix}

Formulae and procedures for the estimation of economic pricing parameters (limited to those used by the analysis)

1.a. (Standard sectoral) conversion factor (weighted average tariff and subsidy rate method): $C F=[X+M] /\left[X\left(1-t_{x}\right)+M\left(1+t_{m}\right)\right]$

1.b Schydlowsky's conversion factor (force of tariff method):

$$
\mathrm{CF}_{\mathrm{FT}}=\mathrm{M} / \mathrm{M}\left(1+\mathrm{t}_{\mathrm{m}}\right)
$$

2. Social opportunity cost of capital at border prices:

$\mathrm{q}=\mathrm{MPK}\left(\mathrm{SCF} / \mathrm{CF}_{\mathrm{k}}\right)$, where

MPK $=\Delta Q / \Delta K=\alpha Q / K$ and $\alpha$ is estimated from

$\mathrm{Q}=\mathrm{AK}^{\alpha} \mathrm{L}^{\mathrm{\beta}}$

3. $\mathrm{CRI}=\mathrm{ng}+\rho$

4. Value of public income (or shadow price of capital) $v=q /\left(\mathrm{CF}_{\mathrm{c}} \cdot \mathrm{CRI}\right)$

5. $A R I=s q+\left[(1-s) q /\left(v \cdot C F_{c}\right)\right]$

6. $(\mathrm{SER}=\mathrm{OER} / \mathrm{SCF})$

\section{Explanation of symbols}

ARI accounting rate of interest

CRI consumption rate of interest

OER official exchange rate

$S C F$ standard conversion factor

SER shadow exchange rate

SRD social rate of discount

$\mathrm{CF}_{\mathrm{c}}$ sectoral conversion factor for consumer goods

$\mathrm{CF}_{\mathrm{k}}$ sectoral conversion factor for capital goods

$M$ imports (c.i.f)

X exports (f.o.b)

L. average import tariff rate

$t_{x}$ average export tax (negative in the case of export subsidy)

MPK marginal productivity of capital

Q production

K fixed capital stock

L employment

n (with minus sign) social elasticity of the marginal utility of consumption (i.e. society's aversion to inequality) (notes 12 and 13)

g growth rate of real per capita consumption

$\rho$ social time-preference rates

$s \quad$ marginal saving propensity 